\title{
Methods for assessing the value of innovative industrial products in agribusiness
}

\author{
Svetlana Lapteva ${ }^{1}$, Alexey Efimiev $^{2}$, Margarita Agafonova, ${ }^{2, *}$ and Andrei Vtornikov $^{2}$ \\ ${ }^{1}$ Moscow State University of Civil Engineering, 26, Yaroslavskoe Shosse, 129337, Moscow, Russia \\ ${ }^{2}$ Voronezh State Technical University, 14, Moscovskiy prospect, 394026, Voronezh, Russia
}

\begin{abstract}
The purpose of this study is to develop a methodology for assessing the cost of innovative products in the field of industrial production in agribusiness, adequate to the processes of reducing the life cycle of innovations and increasing the share of the intellectual component in its value. A multifactor model for assessing the value of industrial products has been formed, on the basis of which a system of assessment criteria has been developed, covering the functional orientation and degree of radicalism of innovation. As a result, a comprehensive analytical model for assessing the value of the intellectual component of innovative industrial products in agribusiness was obtained, covering commodity, product, technological, organizational, and managerial groups.
\end{abstract}

\section{Introduction}

Typical objectives of assessing the value of innovative industrial products are to increase the market value of the enterprise, ensure that all assets of the enterprise are accounted for, reduce income taxes, regulate depreciation, optimize the ratio of assets, take into account the value of assets during the reorganization, liquidation or bankruptcy of an enterprise.

The studies have shown that in the context of accelerating scientific and technological progress and the formation of a knowledge economy as an independent sphere of the economy, the market share of innovative industrial products is increasing, accompanied by the development of methods for assessing them in various areas [1].

On this basis, traditional methods of cost of innovative industrial products are further developed, including:

- sales comparison method;

- income method;

- cost plus method;

- cash flow discounting method.

The importance of the area related to the preparation of initial data for the assessment, which is based on an analysis of the main development trends, and the expected growth rates of the market segment is growing.

\footnotetext{
*Corresponding author: agaf-econ@ yandex.ru
} 


\section{Materials and Methods}

The studies in the field of estimating the value of innovative industrial products (including the evaluation of inventions, computer software, industrial designs, utility models, brand names and appellations of origin, know-how as production secrets; databases and topologies of integrated circuits) showed that the key problems are as follows:

- the cost of an innovative product is estimated in relation to the entire facility as a whole, which makes it difficult to assess the value of the intellectual component;

- estimation of value added arising as a result of the materialization of intellectual labor when creating innovative products;

- estimation of the cost of innovative industrial products is caused by the fact that the lifetime, and, consequently, the useful life of the entire innovative product and its intellectual component may not coincide.

There are a number of other problems, among which the main one is the calculation of the discount rate during the assessment of intellectual property, taking into account the risks of investing in the assessed object.

Based on the identification of the problems of estimating the cost of innovative industrial products, an algorithm for solving them has been formed in the study (Fig. 1), which provides an analysis of the assessment features aimed at creating a universal model [2].

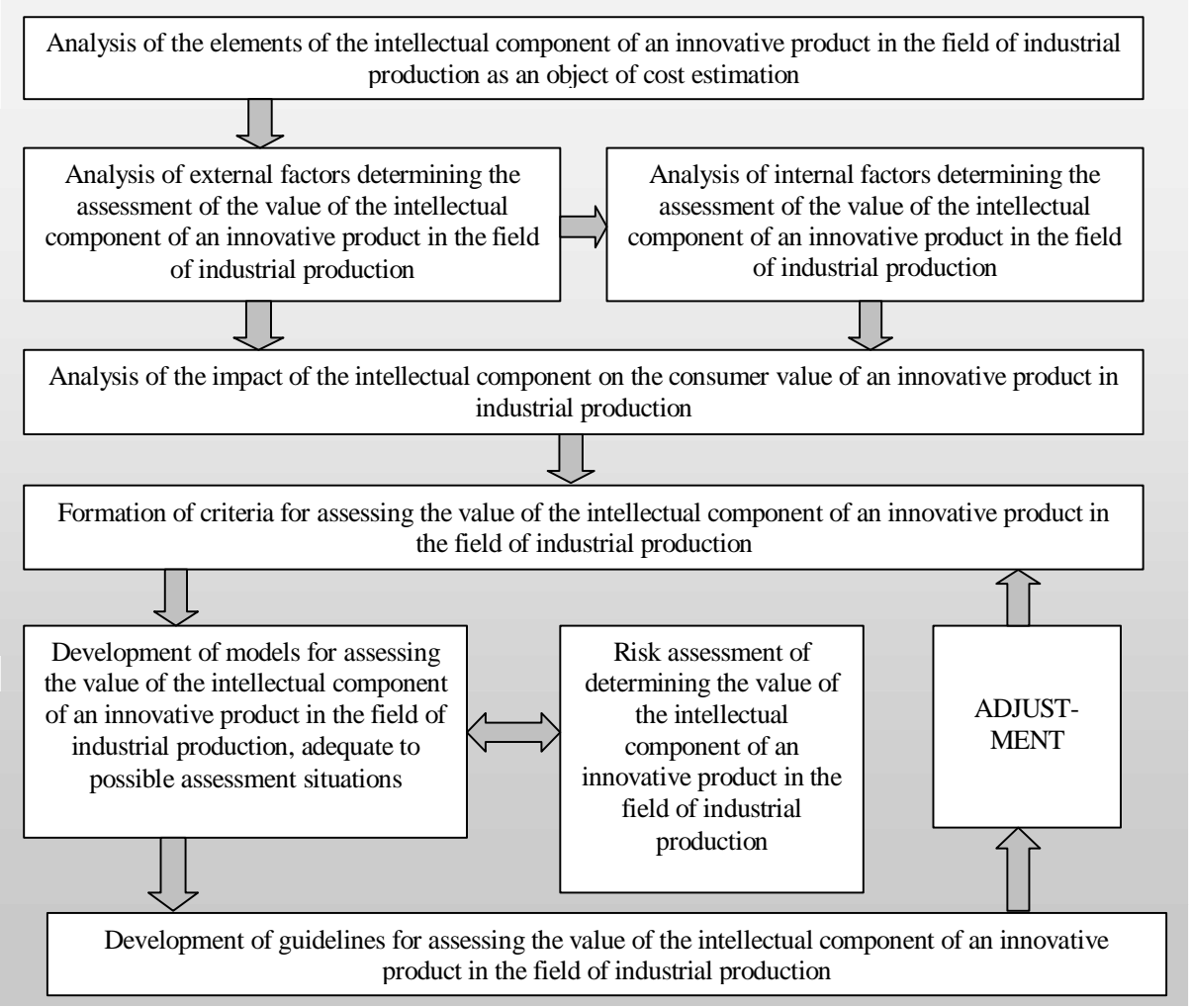

Fig. 1. Algorithm for solving problems of estimating the cost of innovative industrial products.

Obtaining an estimate of the cost of an innovative product, which confirms the significant impact of intellectual work on the value added and profit, is designed to increase 
the practical interest of investors in the development of innovative activities in the field of industrial production.

Traditionally, in the field of industrial production, it is customary to distinguish three stages of transformation of intellectual capital when creating innovative products:

- conversion of investments into intellectual elements of productive capital;

- transformation of the intellectual elements of capital into the intellectual component of innovative products;

- transformation of innovative products from a commodity form into a cash form as a result of a purchase and sale transaction, which provides the possibility of further innovative development of the enterprise.

Moreover, with regard to innovative products in the field of industrial production, three groups of intellectual property are traditionally distinguished (Fig. 2).

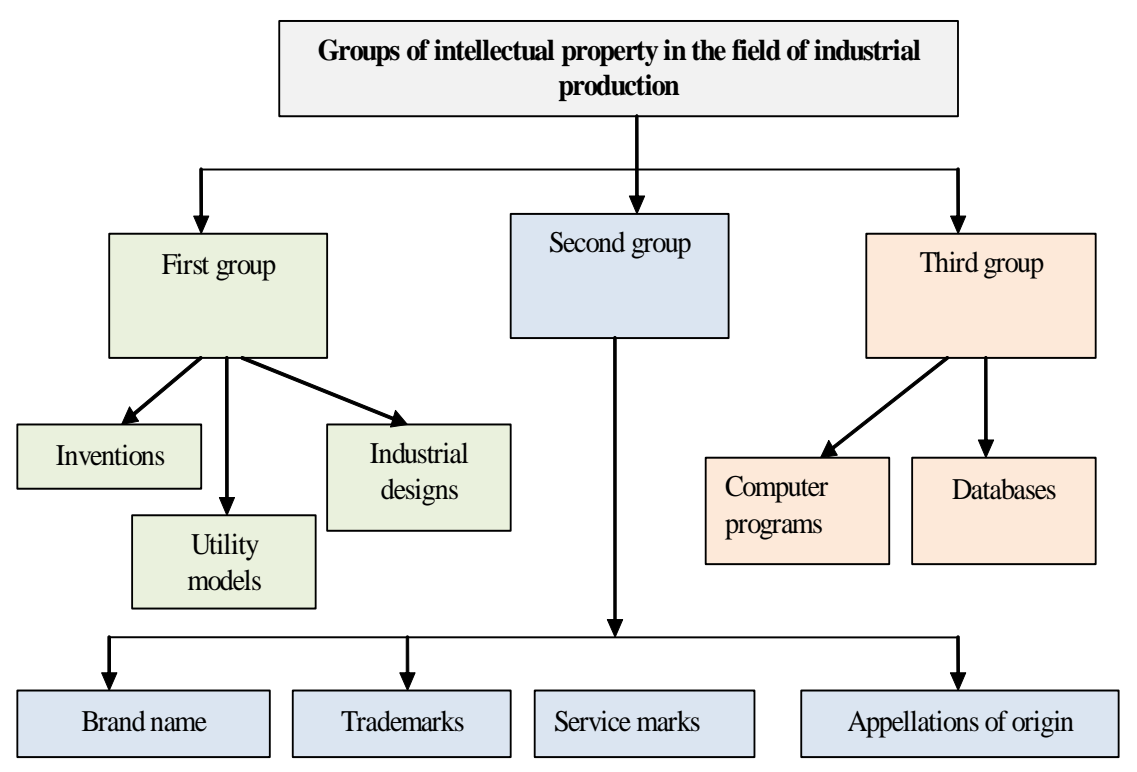

Fig. 2. Groups of intellectual property in the field of industrial production.

Thus, it is traditionally accepted to allocate nine elements of the intellectual component of innovative industrial products according to the stages of transformation of intellectual capital and groups of intellectual property $[3,4,5]$.

However, a detailed analysis of the described traditional approach shows that the selection of elements of innovative industrial products as an object of cost estimation is almost absent in it, since the cost is estimated only at one stage of transformation of intellectual capital in relation to one of the objects of intellectual property.

In this regard, an approach is proposed in which it is proposed to highlight the elements of an innovative product in relation to all stages of the innovation process and to innovations of different functional orientations according to J. Schumpeter's classification.

The matrix of elements of the intellectual component of an innovative product as applied to all stages of the innovation process, which unites objects of innovative industrial products, has the following form:

$$
|A|=\left|\begin{array}{cccc}
a_{11} & a_{12} & \ldots & a_{1 n} \\
a_{21} & a_{22} & \ldots & a_{2 n} \\
\ldots & \ldots & a_{i j} & \ldots \\
a_{m 1} & a_{m 2} & \ldots & a_{m n}
\end{array}\right|,
$$


where $a_{i j}$ - an element of an innovative product corresponding to the i-th stage of the innovation process and for the $\mathrm{j}$-th functional orientation of innovation,

$\mathrm{m}$ - stages of the innovation process, including:

- marketing research,

- basic research,

- research work,

- development work,

- tests in market conditions,

- design preparation of production,

- technological preparation of production,

- organizational preparation of production,

- development of production,

- bringing innovation to the market,

- growth in production volumes;

- achievement of maturity (modernization);

- decline in production volumes.

$\mathrm{n}$ - functional areas of innovation, including:

- commodity innovations,

- product innovations,

- technological innovations,

- organizational innovations,

- market innovations.

The matrix of elements of innovative industrial products $|A|$ formed in the system "stages of the innovation process - the functional focus of innovations" allows determining the added value for each element and forming a matrix of added value of the innovative product $|D|$ :

$$
|D|=\left|\begin{array}{cccc}
d_{11} & d_{12} & \ldots & d_{1 n} \\
d_{21} & d_{22} & \ldots & d_{2 n} \\
\ldots & \ldots & d_{i j} & \ldots \\
d_{m 1} & d_{m 2} & \ldots & d_{m n}
\end{array}\right|
$$

where $d_{i j}$ - the added value for the elements of the innovative product, corresponding to the $\mathrm{i}$-th stage of the innovation process and for the $\mathrm{j}$-th functional orientation of innovation.

Allocating the cost of the intellectual component $f_{i j}$ in each element of the matrix $|D|$ on the basis of the principle of labor reduction:

$$
f_{i j}=d_{i j}-g_{i j}
$$

where $g_{i j}$ - the share of the cost of the traditional component, corresponding to the i-th stage of the innovation process and for the $\mathrm{j}$-th functional orientation of innovation, it is possible to build a matrix of elements of the intellectual component of the added value of the innovative product: 


$$
|F|=\left|\begin{array}{cccc}
f_{11} & f_{12} & \ldots & f_{1 n} \\
f_{21} & f_{22} & \ldots & f_{2 n} \\
\ldots & \ldots & f_{i j} & \ldots \\
f_{m 1} & f_{m 2} & \ldots & f_{m n}
\end{array}\right| .
$$

Thus, as a result of the analysis of elements of innovative products of industrial production as an object of cost estimation, a matrix of elements of the intellectual component of added value was formed. The assessment by the formed matrix corresponds to the excess profit method of the income approach, which means that the innovative product has competitive advantages in terms of components $f_{i j}>0$, i.e. it is estimated above the average level.

\section{Results}

Based on the allocation of elements of innovative industrial products as an object of cost estimation, a factor model for assessing the impact of the intellectual component on consumer value is developed in this study (Fig. 3).

The presented model indicates that under the influence of external factors of direct and indirect impact, the internal inducing factors of creating innovative products affect the internal controlled factors that provide market results of the emergence of innovations as objects of intellectual property [6]. Based on the assessment of the value of an innovative product as an object of intellectual property, one of the well-known approaches is used to assess the added value of an innovative product and then allocate it on the basis of the income approach.

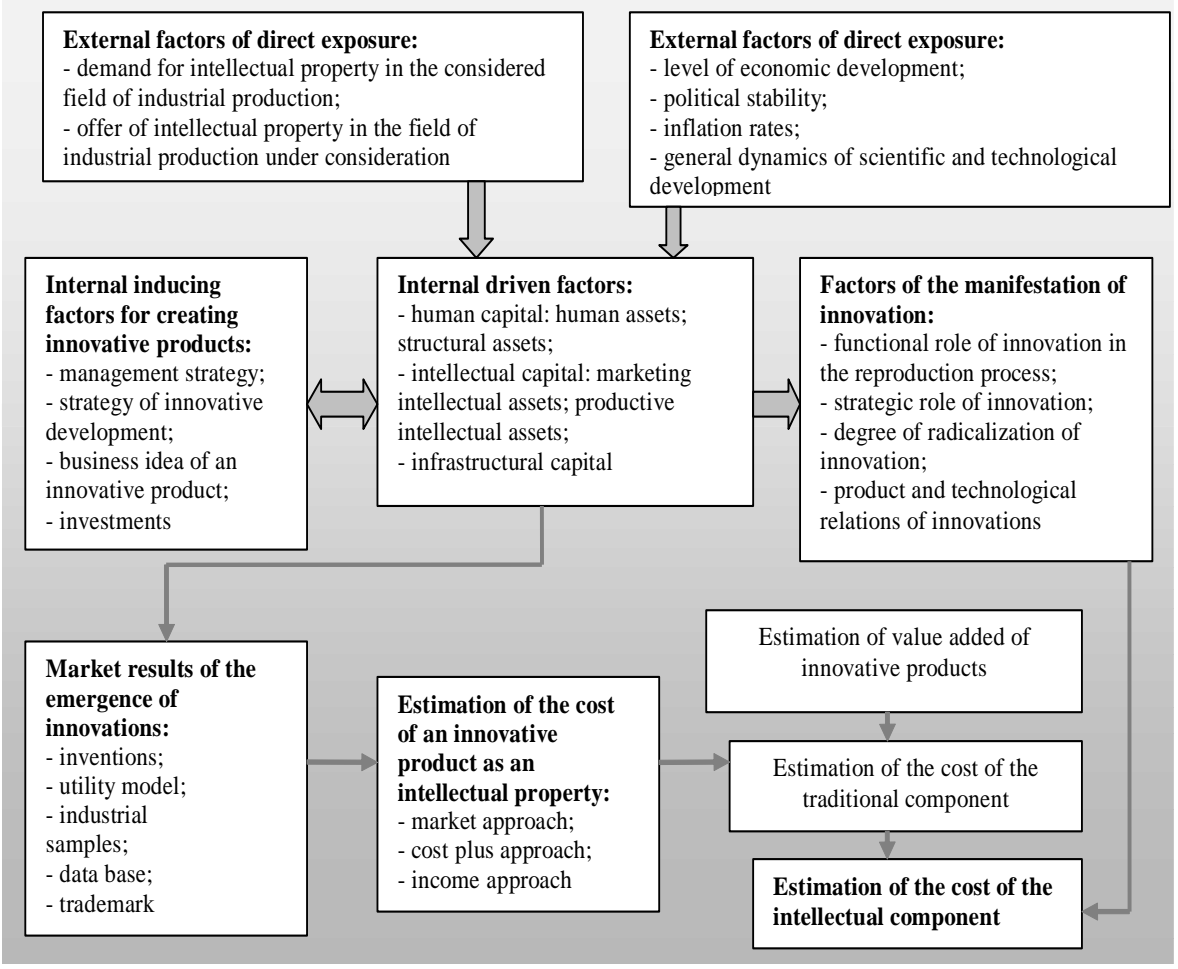

Fig. 3. Factor model for assessing the impact of innovative industrial products. 
When assessing the value of the intellectual component of an innovative product, factors of the manifestation of innovations should be taken into account, starting from the functional role of innovation in the reproduction process and ending with the assessment of the ratios of product and technological innovations [7, 8].

6. When solving the scientific problem of improving approaches to assessing the value of innovative industrial products based on the conducted analytical studies, evaluation criteria were formed $[9,10]$.

The developed criteria are based on the formed functions (formulas 2, 3 and 4).

Based on the value added matrix of an innovative product $|D|$, it is possible to determine the expected value of the value added of an innovative product $D S_{p}$ by summing up the results for all stages of the innovation process and all the functional areas of innovation:

$$
D S_{p}=\sum_{i=1}^{m} \sum_{j=1}^{n} d_{i j}
$$

The criterion (formula 5) can be used in assessing the value of the intellectual component of an innovative product created during the implementation of an in-house innovation process. An example of an in-house innovation process can be, for example, key technology, when an enterprise implements advanced technology that ensures competitiveness and a leading position in the current period of time.

Taking into account the criterion (formula 5) and the model (formula 4), the intellectual component of the added value of an innovative product can be estimated by the criterion:

$$
F_{p}=\sum_{i=1}^{m} \sum_{j=1}^{n}\left(d_{i j}-g_{i j}\right) .
$$

For cases of the implementation of a simple and expanded innovation process for the values of the intellectual component of the added value of the innovative product $f_{i j}$, according to the elements corresponding to the $\mathrm{i}$-th stage of the innovation process and for the $\mathrm{j}$-th functional orientation of the innovation, it is advisable to introduce reduction factors $\lambda_{i j}$ characterizing the level of possible replication of the corresponding intellectual component of the innovative product:

$$
F_{\lambda}=\sum_{i=1}^{m} \sum_{j=1}^{n}\left(d_{i j}-g_{i j}\right) \cdot \lambda_{i j}
$$

If innovation has a modifying short-term nature, then a criterion (formula 7) may be sufficient. However, if the innovation is radical, then there is a need to take into account the time factor, since the values of added value $d_{i j}$, cost of the traditional component $g_{i j}$ and reduction ratio $\lambda_{i j}$ change simultaneously:

$$
F_{\lambda}(t)=\int_{t} \sum_{i=1}^{m} \sum_{j=1}^{n}\left[d_{i j}(t)-g_{i j}(t)\right] \cdot \lambda_{i j}(t) .
$$

Thus, the proposed system of criteria for assessing the value of the intellectual component of an innovative product covers: stages of the innovation process, the functional orientation of innovations, forms of the innovation process and the degree of radicalization of innovations. 
7. The formed criteria for assessing the value of innovative industrial products have allowed developing a comprehensive analytical model adequate to possible assessment situations.

The developed complex analytical model is presented in the form of a sequence (algorithm) of selecting adequate models for assessing the cost of an innovative industrial product (table 1).

The generated algorithm allows determining one of four models for assessing an innovative industrial product for nine possible situations of assessment in the system "degree of radicalization of innovations - form of the innovation process":

1. Cost estimation model without taking into account the reduction coefficient $\lambda_{i j}$ and dynamics of parameters $\lambda_{i j}, d_{i j}$ and $g_{i j}$.

2. Cost estimation model taking into account the reduction coefficient $\lambda_{i j}$ and without taking into account the dynamics of parameters $d_{i j}$ and $g_{i j}$.

3. Cost estimation model without taking into account the reduction coefficient $\lambda_{i j}$ and taking into account the dynamics of the parameters $\lambda_{i j}, d_{i j}$ and $g_{i j}$.

4. Cost estimation model taking into account the reduction coefficient $\lambda_{i j}$ and dynamics of parameters $d_{i j}$ and $g_{i j}$.

The studies of the risks inherent in estimates of the cost of innovative industrial products have shown that the use of the proposed models can improve the reliability of the estimates made.

Table 1. The sequence of the procedure for selecting models for assessing the value of innovative industrial products.

\begin{tabular}{|c|c|c|c|}
\hline $\begin{array}{c}\text { Assessment } \\
\text { models }\end{array}$ & Stage & Stage 2 & Stage 3 \\
\hline Rationalization & $\begin{array}{l}F_{p} \\
=\sum_{\substack{\left.i=1 \\
-g_{i j}\right)}}^{m}\end{array}$ & $\begin{array}{l}F_{p} \\
=\sum_{\substack{\left.i=1 \\
-g_{i j}\right)}}^{m}\end{array}$ & $=\sum_{\substack{\left.i=1 \\
-g_{i j}\right) \cdot \lambda_{i j}}}^{F_{\lambda}} \sum_{j=1}^{n}$ \\
\hline Modernization & $=\sum_{\substack{\left.i=1 \\
-g_{i j}\right)}}^{F_{p}} \sum_{j=}^{r}$ & $=\sum_{\substack{\left.i=1 \\
-g_{i j}\right) \cdot \lambda_{i j}}}^{F_{\lambda}} \sum_{j=}^{r}$ & $=\sum_{\substack{\left.i=1 \\
-g_{i j}\right) \cdot \lambda_{i j}}}^{F_{\lambda}} \sum_{j=1}^{n}$ \\
\hline Radical & \multicolumn{3}{|c|}{$F_{\lambda}(t)=$} \\
\hline
\end{tabular}




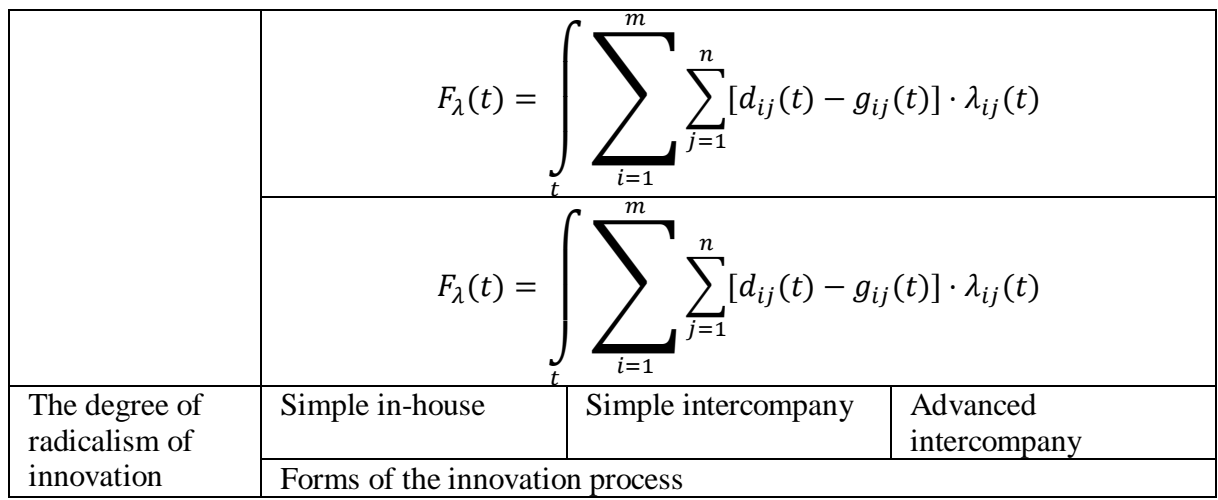

If in traditional approaches to determining risks of cost estimation external risks, market risks and internal risks (including the lack of scientific and technical potential, the inaccuracy of scientific and technical forecasts) are traditionally taken into account, then the proposed approach additionally takes into account:

- intellectual component of the added value of an innovative product $f_{i j}$ according to the elements corresponding to the stages of the innovation process and the functional orientation of innovations,

- coefficient of reduction of the elements of the intellectual component $\lambda_{i j}$,

- dynamics of parameters $\lambda_{i j}, d_{i j}$ and $g_{i j}$.

Thus, the risk of assessing the value of the intellectual component of an innovative product in the field of industrial production can be represented in the form of a model:

$$
\sigma_{f}=\sqrt{\sigma_{1}^{2}+\sigma_{2}^{2}+\sigma_{3}^{2}+\sigma_{4}^{2}+\sigma_{5}^{2}+\sigma_{6}^{2}}
$$

where $\sigma_{1}^{2}$ - the variance of cost estimates based on external risks,

$\sigma_{2}^{2}$ - the variance of cost estimates based on market risks,

$\sigma_{3}^{2}$ - the variance of cost estimates based on internal risks,

$\sigma_{4}^{2}$ - the variance of the estimation based on the risks of assessing the component of the added value of the innovative product $f_{i j}$ according to the elements corresponding to the stages of the innovation process and the functional orientation of innovations,

$\sigma_{5}^{2}$ - the variance of cost estimates based on the risks of determining the reduction coefficient of the elements of the intellectual component $\lambda_{i j}$,

$\sigma_{6}^{2}$ - the variance of cost estimates based on the risks of determining the dynamics of the parameters $\lambda_{i j}, d_{i j}$ and $g_{i j}$. 


\section{Conclusion}

The proposed model for assessing risks in the production of innovative products was tested using the example of several enterprises in the industry and showed a reduction in risks in all the main areas of research.

Thus, the developed comprehensive analytical model for assessing the value of innovative industrial products, adequate to possible assessment situations, allows determining the characteristics of commodity, product, technological, organizational, managerial, and market innovations at all stages of the innovation process.

\section{References}

1. R. Golov, T. Narezhnaya, MATEC Web of Conferences (2018) https://doi.org/10.1051/matecconf/201819305080

2. I. Lukmanova, R. Golov, E3S Web of Conferences 33 (2018) https://doi.org/10.1051/e3sconf/20183302047

3. R.K. Gorshkov, O.E. Roshchina, Procedia Engineering 165, 1332-1336 (2016)

4. S. Uvarova, V. Vlasenko, E3S Web of Conferences 33, 03022 (2018)

5. O. Belyantseva, A. Panenkov, N. Safonova, IOP Conference Series: Earth and Environmental Science 90(1), 012167 (2017)

6. K. Gumba, O. Belyantseva, L. Kochetova, Procedia Engineering 165, 1323-1327 (2016)

7. R. Golov, M. Pushkareva, E3S Web Conf. 110 https://doi.org/10.1051/e3sconf/201911002134

8. O.J. Kravets, E.S. Podvalny, S.A. Barkalov, Automation and Remote Control 76(3), 500-506 (2015)

9. V. Poryadina, V. Burkov, S. Barkalov, I. Ilin, O. Kalinina, MATEC Web of Conferences conference proceedings, 01122 (2018)

10. S. Uvarova, O. Kutsygina, E. Smorodina, K. Gumba, E3S Web of Conferences, 03024 (2018) 